\title{
Intraoperative prediction of cardiac surgery-associated acute kidney injury using urinary biomarkers of cell cycle arrest
}

Jared J. Cummings, MD, ${ }^{a}$ Andrew D. Shaw, MB, FRCA, ${ }^{a}$ Jing Shi, PhD, ${ }^{b}$ Marcos G. Lopez, MD, MS, Jason B. O'Neal, MD, and Frederic T. Billings IV, MD, MSc ${ }^{\text {a,c }}$

\section{ABSTRACT}

Objective: Tissue inhibitor of metalloproteinases 2 (TIMP-2) and insulin-like growth factor-binding protein 7 (IGFBP7) are postoperative urinary biomarkers of renal stress and acute kidney injury (AKI). We conducted this study to test the hypothesis that intraoperative concentrations of urinary [TIMP-2]·[IGFBP7] are associated with postoperative AKI.

Methods: We measured urinary [TIMP-2]·[IGFBP7] at 8 perioperative timepoints in 400 patients who participated in a randomized controlled trial of atorvastatin for AKI in cardiac surgery. We compared [TIMP-2]·[IGFBP7] between subjects who did and did not develop KDIGO stage 2 or 3 AKI within 48 hours of surgery, adjusted for AKI risk factors.

Results: Fourteen patients (3.5\%) met the primary endpoint of stage 2 or 3 AKI within 48 hours of surgery, and an additional 77 patients (19.3\%) developed stage 1 AKI. Patients who developed stage 2 or 3 AKI displayed bimodal elevations of [TIMP-2]·[IGFBP7], with a first elevation (median, $0.45[\mathrm{ng} / \mathrm{mL}]^{2} / 1000$ ) intraoperatively and a second elevation $\left(1.45 \quad[\mathrm{ng} / \mathrm{mL}]^{2} / 1000\right) 6$ hours postoperatively. Patients who did not develop AKI did not have any elevations in [TIMP-2]-[IGFBP7]. Each 10-fold increase in intraoperative [TIMP-2] [IGFBP7] was independently associated with a $290 \%$ increase in the odds of stage 2 or 3 AKI $(P=.01)$, and each 10 -fold increase in the 6 hours postoperative [TIMP-2] [ [IGFBP7] was independently associated with a $650 \%$ increase in the odds of stage 2 or 3 AKI $(P<.001)$. The maximum [TIMP-2] [ [IGFBP7] between these 2 timepoints provided an area under the receiver operating characteristic curve of 0.82 (95\% confidence interval [CI], 0.73-0.90), 100\% sensitivity, and $100 \%$ negative predictive value using the $>0.3$ cutoff to predict stage 2 or 3 AKI.

Conclusions: Intraoperative elevations of [TIMP-2]·[IGFBP7] can predict moderate or severe AKI and could provide an opportunity to alter postoperative management to prevent kidney injury. (J Thorac Cardiovasc Surg 2019;157:1545-53)

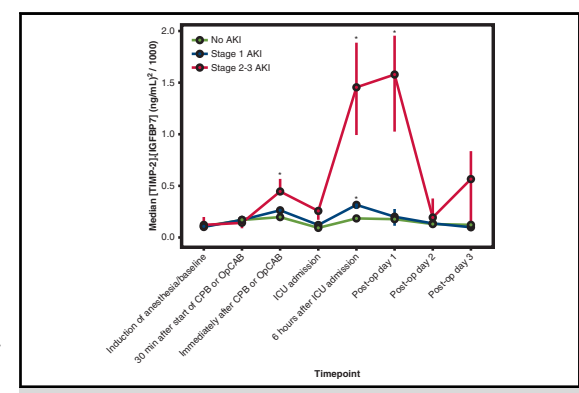

Perioperative urinary [TIMP-2]·[IGFBP7]

Central Message

Intraoperative elevations of [TIMP-2]. [IGFBP7] can predict moderate or severe AKI and could provide opportunity to alter postoperative management to prevent kidney injury.

\section{Perspective}

This study provides first evidence that AKI following cardiac surgery can be predicted with intraoperative urine biomarker measurements and that patients who develop moderate or severe AKI experience both intraoperative and early postoperative renal stress. These markers provided $100 \%$ sensitivity to predict AKI and $100 \%$ negative predictive value to identify patients who would not develop AKI.

See Commentary on page 1554 .

Supplemental material is available online.

\footnotetext{
From the Divisions of a Cardiothoracic Anesthesiology and ${ }^{\mathrm{c} C r i t i c a l}$ Care Medicine, Department of Anesthesiology, Vanderbilt University Medical Center, Nashville, Tenn; and the ${ }^{\mathrm{b}}$ Department of Statistics, Walker Bioscience, Carlsbad, Calif. Supported by grants T32GM108554, K23GM102676, R01GM112871, and UL1TR000445 from the National Institutes of Health; a grant from the Foundation for Anesthesia Education and Research; and by the Vanderbilt University Medical Center Department of Anesthesiology.

Received for publication Feb 22, 2018; revisions received July 12, 2018; accepted for publication Aug 7, 2018; available ahead of print Oct 30, 2018.

Address for reprints: Frederic T. Billings IV, MD, MSc, 1161 21st Ave South, T-4202 MCN Nashville, TN 37232 (E-mail: frederic.t.billings@vanderbilt.edu). $0022-5223 / \$ 36.00$

Copyright (c) 2018 by The American Association for Thoracic Surgery https://doi.org/10.1016/j.jtcvs.2018.08.090
}

- Video clip is available online.

Acute kidney injury (AKI) is one of the most serious and common complications of cardiac surgery. A recent systematic review and meta-analysis reported that cardiac surgeryassociated (CSA)-AKI affects $22.3 \%$ of patients, approximately 450,000 of the 2 million patients who receive cardiac surgery annually. ${ }^{1,2}$ The Society of Thoracic Surgery 


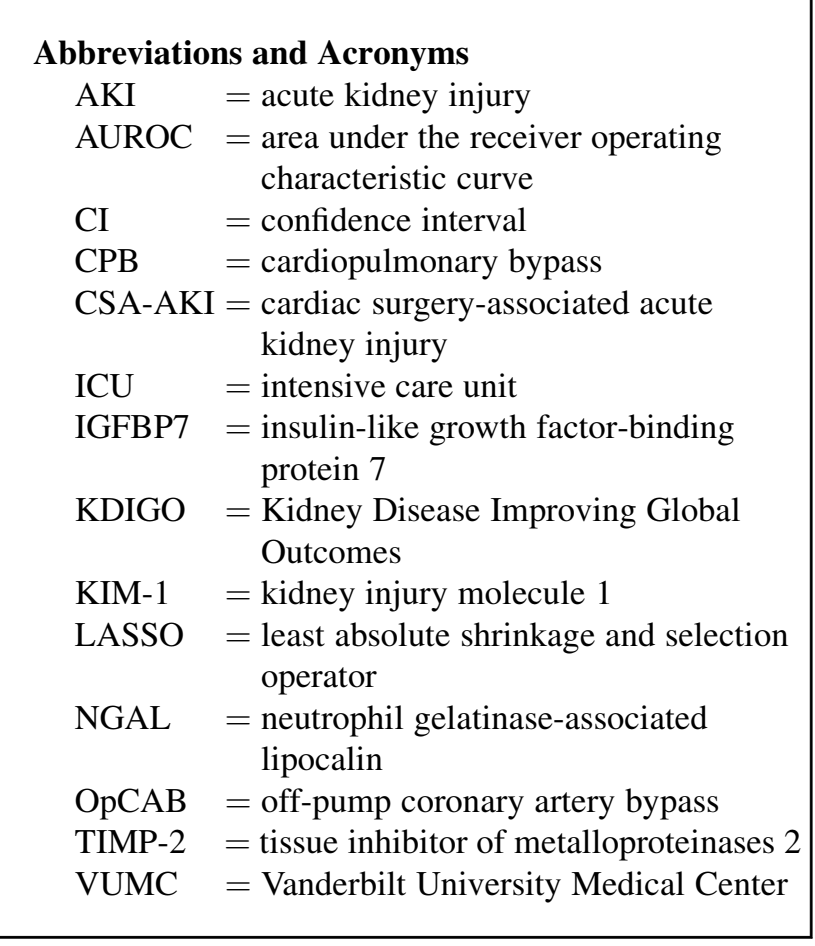

National Database reports that $2.3 \%$ of cardiac surgery patients develop renal failure (stage $3 \mathrm{AKI}$ ), defined as a $200 \%$ increase in serum creatinine, creatinine exceeding $4.0 \mathrm{mg} / \mathrm{dL}$ with a minimum increase of $0.5 \mathrm{mg} / \mathrm{dL}$, or dialysis. ${ }^{3}$ CSA-AKI is independently associated with postoperative morbidity and mortality, with severe AKI being independently associated with up to an 8-fold increase in perioperative mortality, a prolonged length of stay, and increased cost. ${ }^{4,5}$ The mechanisms of CSA-AKI include renal ischemia-reperfusion, inflammation, hemolysis, oxidative damage, and nephrotoxin exposure. ${ }^{4,6}$

Current diagnostic criteria for AKI rely on changes in serum creatinine ( $\mathrm{SCr}$ ) or urine output, which reflect kidney function, as a surrogate for injury. Single values of $\mathrm{SCr}$ during acute evolution of renal dysfunction will underestimate the degree of dysfunction. ${ }^{7,8}$ Thus, diagnosis of AKI is typically time delayed from the actual renal insult. Furthermore, hemodilution during cardiopulmonary bypass (CPB), volume resuscitation, and mannitol administration can confound the use of these criteria to diagnose AKI in cardiac surgery patients. ${ }^{4}$

Identification of biomarkers reflective of kidney injury and stress might allow clinicians to identify renal injury earlier, thus providing opportunities for intervention. The biomarkers neutrophil gelatinase-associated lipocalin (NGAL), kidney injury molecule-1 (KIM-1), and cystatin $C$ have been studied for this purpose. The area under the receiver operating characteristic curve (AUROC) for these markers to predict CSAAKI, however, remains modest ( 0.67 for NGAL, 0.65 for KIM-1, and 0.71 for cystatin C). ${ }^{9,10}$
Recently, urine tissue inhibitor of metalloproteinases 2 (TIMP-2) and insulin-like growth factor-binding protein 7 (IGFBP7) have been identified as early biomarkers associated with AKI. ${ }^{11}$ During cellular stress caused by conditions such as ischemia or sepsis, renal epithelial cells undergo G1 cell cycle arrest to prevent potential damage to DNA during replication. ${ }^{12}$ TIMP-2 and IGFBP7 are 2 proteins expressed during cell cycle arrest. In the past several years, the product of these markers, [TIMP-2] -[IGFBP7], has been validated to predict the development of Kidney Disease Improving Global Outcomes (KDIGO) ${ }^{13}$ stage 2 or 3 (moderate or severe) AKI in cardiac surgery, ${ }^{14,15}$ noncardiac surgery, ${ }^{16,17}$ and intensive care unit (ICU) patient populations. ${ }^{11,18}$ In fact, studies have shown that measurement of [TIMP-2]. [IGFBP7] as early as intensive care unit admission can discriminate between patients who will and will not develop KDIGO stage 2 or 3 AKI after cardiac surgery. ${ }^{14,15}$ These studies have shown [TIMP-2] [IGFBP7] to be a moderate to good predictor of AKI with an AUROC between 0.80 and 0.90 .

It remains unclear, however, if urinary [TIMP-2] · [IGFBP7] rises even earlier in the perioperative course, such as during surgery, among patients who subsequently develop AKI. Many of the insults responsible for CSA-AKI, such as ischemia reperfusion, hemolysis, and oxidative damage, occur intraoperatively. ${ }^{2,4,6,19,20}$ Intraoperative identification of patients with a high likelihood of developing AKI might provide physicians an early opportunity to initiate monitoring and treatment regimens to reduce AKI.

We conducted this study to test the hypothesis that intraoperative concentrations of urinary [TIMP-2] [ [IGFBP7] are associated with postoperative AKI and to elucidate the perioperative expression of urinary [TIMP-2] [IGFBP7] in patients who do and do not develop AKI.

\section{METHODS}

\section{Study Participants}

This prospective cohort study used urine specimens collected during a previously published trial of statin therapy for prevention of AKI in cardiac surgery. $^{21}$ The Statin AKI Cardiac Surgery study was a randomized, doubleblinded, placebo-controlled trial that enrolled patients between November 2009 and December 2014 to test the efficacy of perioperative atorvastatin administration for reducing CSA-AKI. All adult patients undergoing elective coronary bypass grafting, valvular heart surgery, or ascending aortic surgery at Vanderbilt University Medical Center (VUMC) were eligible for inclusion. Patients with prior statin intolerance, acute coronary syndrome, liver dysfunction, current use of CYP3A4 inhibitors, current use of cyclosporine, current use of renal replacement therapy, history of kidney transplant, urgent or emergent surgery, or pregnancy were excluded from participation. The study was approved by the VUMC institutional review board and conducted in accordance with the Declaration of Helsinki. All patients provided informed written consent.

\section{Procedures}

All patients received surgical, anesthetic, and critical care management according to the standard of care of the medical center, as described previously. ${ }^{21}$ Fresh urine specimens were obtained after induction of anesthesia (baseline), 30 minutes after initiation of $\mathrm{CPB}$ or off-pump coronary 


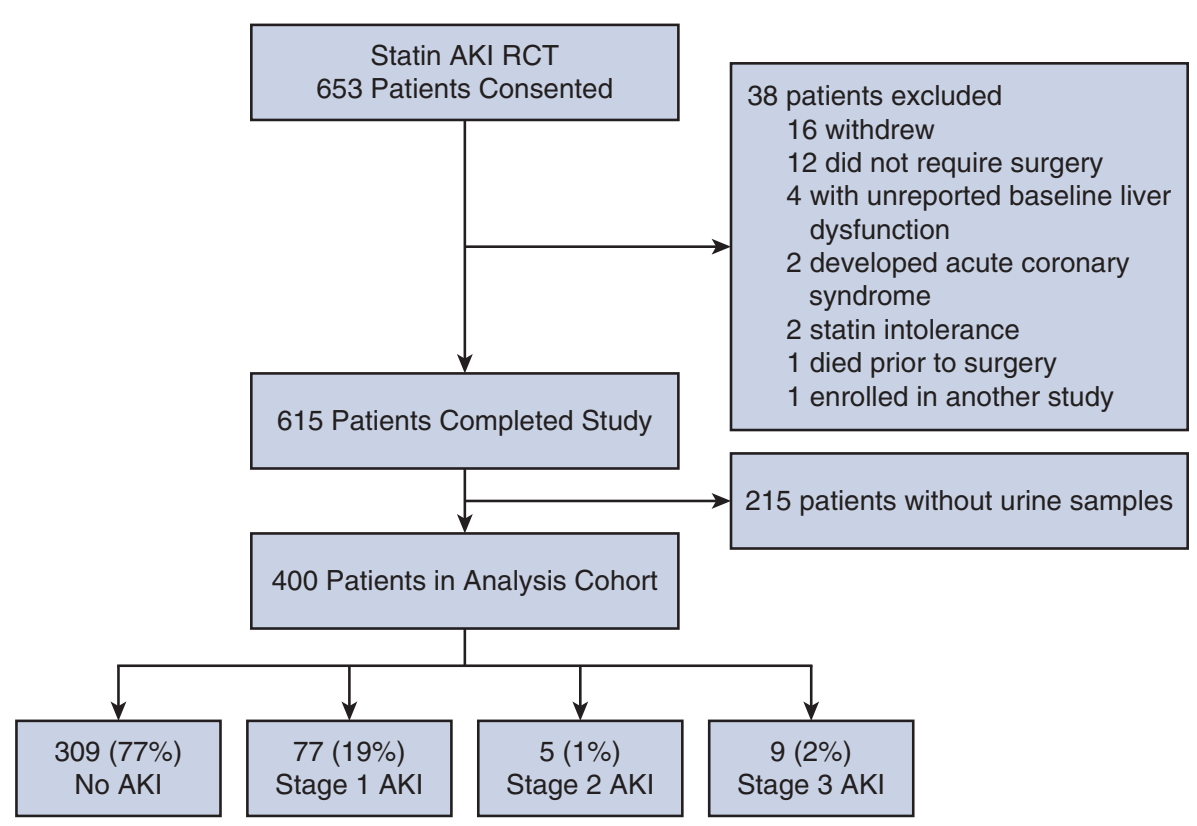

FIGURE 1. Consort diagram. Acute kidney injury ( $A K I$ ) status is the maximum Kidney Disease Improving Global Outcomes (KDIGO) stage reached within 48 hours of surgery. $R C T$, Randomized clinical trial.

artery grafting $(\mathrm{OpCAB})$, immediately after the completion of $\mathrm{CPB}$ or Op$\mathrm{CAB}$, upon ICU admission, 6 hours after ICU admission, and at 9:00 AM on postoperative days 1,2 , and 3 . Samples were collected on ice and centrifuged at $1000 \times g$ for 15 minutes, and the supernatant was frozen at $-80^{\circ} \mathrm{C}$ until thawing for measurement. [TIMP-2]·[IGFBP7] was measured using the commercially available NephroCheck (Astute Medical Inc, San Diego, Calif) test by laboratory personnel blinded to all subject characteristics.

\section{Outcomes}

The primary endpoint was stage 2 or 3 (moderate or severe) AKI occurring within 48 hours of surgery, defined by changes in serum creatinine according to KDIGO criteria. KDIGO criteria define stage 1 $\mathrm{AKI}$ as a $50 \%$ or $0.3-\mathrm{mg} / \mathrm{dL}$ increase in serum creatinine from baseline within 48 hours of surgery; stage 2 AKI as a $100 \%$ increase in serum creatinine; and stage 3 as a $200 \%$ serum creatinine increase, a serum creatinine $>4.0 \mathrm{mg} / \mathrm{dL}$ with an acute rise of $0.5 \mathrm{mg} / \mathrm{dL}$, or initiation of renal replacement therapy. ${ }^{13}$ Secondary endpoints were incidence of renal replacement therapy, ICU and hospital length of stay, ICU readmission, and death.

\section{Statistical Analysis}

To compare the distributions of [TIMP-2] [IGFBP7] among groups with no AKI, stage $1 \mathrm{AKI}$, and stage 2 or 3 AKI at each timepoint, a KruskalWallis test was first performed to test for the global difference among these 3 groups. If there was a significant difference, a post hoc Conover test ( $R$ package "PMCMR") for pairwise multiple comparisons was used to identify which group or groups were significantly different. The $P$ values for pairwise multiple comparisons were adjusted by the Holm method.

We then used multivariable logistic regression to measure the association between [TIMP-2] [ [IGFBP7] and stage 2 or 3 AKI independent from clinical factors associated with AKI. We used least absolute shrinkage and selection operator (LASSO) regression to select a subset of 18 candidate covariates (Table E1) to prevent overfitting and to enhance model interpretation. The data for these 18 candidate variables were power transformed with the Box-Cox procedure to better approximate normal distributions before entering them into the LASSO regression. Body mass index, Thakar score, and baseline hematocrit constituted the final set of model covariates. ${ }^{22}$ The exploratory analysis comparing [TIMP-2]·[IGFBP7] levels with death or dialysis was performed with a Fisher exact test.

The $95 \%$ confidence intervals (CIs) for AUROC metrics and the interquartile ranges of the group medians of [TIMP-2]-[IGFBP7] were estimated by bootstrap. The AUROCs of the baseline clinical model were compared to the AUROCs of the final model (clinical factors in addition to [TIMP-2]·[IGFBP7]) with the "roc.test" function for comparing 2 paired AUROCs in R package "pROC." 23 The continuous Net Reclassification Improvements associated with adding [TIMP-2]. [IGFBP7] to the clinical model was calculated with the "improveProb" function in R package "Hmisc." We performed similar analyses in the subgroup of patients who received cardiopulmonary bypass during surgery. Categorical baseline variables were analyzed using Fisher exact test or chi-squared test, and continuous variables were analyzed using Wilcoxon rank-sum test. Statistical analyses were performed using SAS 9.3 and R3.0. ${ }^{24}$ Two-sided $P$ values $<.05$ were considered statistically significant.

\section{RESULTS}

Four hundred sequential Statin AKI Cardiac Surgery Randomized Clinical Trial patients comprised the cohort. Fourteen of these patients $(3.5 \%)$ developed stage 2 or 3 (moderate or severe) AKI within 48 hours of surgery, 77 patients $(19.3 \%)$ developed stage 1 AKI, and 309 patients $(77.3 \%)$ did not develop AKI (Figure 1). The median age of the cohort was 67 years, $67.3 \%$ of patients were men, the median estimated glomerular filtration rate (eGFR) was $73.2 \mathrm{~mL} / \mathrm{min} / 1.73 \mathrm{~m}^{2}$, and $70.8 \%$ of patients had surgery with CPB (Table 1). Advanced age, a higher Thakar score, and a lower baseline hematocrit were associated with increased stage 2 or 3 AKI (Table E1).

The median urinary [TIMP-2]·[IGFBP7] was 0.11 (ng/ $\mathrm{mL})^{2} / 1000$ at baseline (10th, 90th percentile: $\left.0.02,0.64\right)$, 
TABLE 1. Baseline and intraoperative patient characteristics for all patients and separated into patients who developed no or stage 1 AKI and stage 2 or 3 AKI within 48 hours of surgery

\begin{tabular}{|c|c|c|c|c|}
\hline Characteristic & All $(N=400)$ & No AKI or Stage $1(N=386)$ & Stage 2 or 3 AKI $(N=14)$ & $P$ value \\
\hline Male sex & $269(67.3 \%)$ & $261(67.6 \%)$ & $8(57.1 \%)$ & .40 \\
\hline Age (y) & $67(58-75)$ & $67(58-75)$ & $59(50-71)$ & .04 \\
\hline Body mass index $\left(\mathrm{kg} / \mathrm{m}^{2}\right)$ & $27.4(24.7-31.1)$ & $27.3(24.7-31.0)$ & $31.7(23.0-39.5)$ & .10 \\
\hline $\begin{array}{l}\text { Race } \\
\text { Black or African American } \\
\text { Other } \\
\text { White }\end{array}$ & $\begin{array}{c}19(4.8 \%) \\
5(1.3 \%) \\
376(94.0 \%)\end{array}$ & $\begin{array}{c}18(4.7 \%) \\
5(1.3 \%) \\
363(94.0 \%)\end{array}$ & $\begin{array}{c}1(7.1 \%) \\
0(0 \%) \\
13(92.9 \%)\end{array}$ & .59 \\
\hline $\begin{array}{l}\text { Ethnicity } \\
\text { Hispanic or Latino } \\
\text { Not Hispanic or Latino }\end{array}$ & $\begin{array}{c}6(1.5 \%) \\
394(98.5 \%)\end{array}$ & $\begin{array}{c}6(1.6 \%) \\
380(98.4 \%)\end{array}$ & $\begin{array}{c}0(0 \%) \\
14(100 \%)\end{array}$ & 1.00 \\
\hline \multicolumn{5}{|l|}{ Medical history } \\
\hline Atrial fibrillation & $100(25.0 \%)$ & $96(24.9 \%)$ & $4(28.6 \%)$ & .76 \\
\hline Coronary artery disease & $267(66.8 \%)$ & $258(66.8 \%)$ & $9(64.3 \%)$ & 1.00 \\
\hline Heart failure & $163(40.8 \%)$ & $156(40.4 \%)$ & $7(50.0 \%)$ & .58 \\
\hline Cardiac surgery & $74(18.5 \%)$ & $69(17.9 \%)$ & $5(35.7 \%)$ & .15 \\
\hline CABG & $37(9.3 \%)$ & $36(9.3 \%)$ & $1(7.1 \%)$ & 1.00 \\
\hline Valve surgery & $40(10.0 \%)$ & $36(9.3 \%)$ & $4(28.6 \%)$ & .04 \\
\hline Diabetes & $123(30.8 \%)$ & $120(31.1 \%)$ & $3(21.4 \%)$ & .56 \\
\hline Hypertension & $348(87.0 \%)$ & $335(86.8 \%)$ & $13(92.9 \%)$ & 1.00 \\
\hline Peripheral vascular disease & $113(28.3 \%)$ & $109(28.2 \%)$ & $4(28.6 \%)$ & 1.00 \\
\hline Stroke (CVA) & $22(5.5 \%)$ & $20(5.2 \%)$ & $2(14.3 \%)$ & .18 \\
\hline Transient ischemic attack & $13(3.3 \%)$ & $12(3.1 \%)$ & $1(7.1 \%)$ & .38 \\
\hline Dementia & $5(1.3 \%)$ & $5(1.3 \%)$ & $0(0 \%)$ & 1.00 \\
\hline COPD & $47(11.8 \%)$ & $46(11.9 \%)$ & $1(7.1 \%)$ & 1.00 \\
\hline Obstructive sleep apnea & $57(14.3 \%)$ & $53(13.7 \%)$ & $4(28.6 \%)$ & .12 \\
\hline Current smoker & $67(16.8 \%)$ & $66(17.1 \%)$ & $1(7.1 \%)$ & .48 \\
\hline Charlson Comorbidity Index & $2.0(1.0-4.0)$ & $2.0(1.0-4.0)$ & $4.0(1.0-5.0)$ & .12 \\
\hline LV ejection fraction baseline (\%) & $60.0(50.0-60.0)$ & $60.0(50.0-60.0)$ & $55.0(50.0-60.0)$ & .43 \\
\hline ACE inhibitor use & $125(31.3 \%)$ & $120(31.1 \%)$ & $5(35.7 \%)$ & .77 \\
\hline Atorvastatin treatment & $204(51.0 \%)$ & $197(51.0 \%)$ & $7(50.0 \%)$ & 1.00 \\
\hline eGFR $\left(\mathrm{mL} / \mathrm{min} / 1.73 \mathrm{~m}^{2}\right)$ & $72.3(53.6-87.9)$ & $72.9(54.3-87.9)$ & $45.8(19.9-84.6)$ & .08 \\
\hline $\begin{array}{l}\text { CKD stage } \\
\qquad \begin{array}{l}1\left(\text { eGFR }>90 \mathrm{~mL} / \mathrm{min} / 1.73 \mathrm{~m}^{2}\right) \\
2\left(\text { eGFR } 60-90 \mathrm{~mL} / \mathrm{min} / 1.73 \mathrm{~m}^{2}\right) \\
3\left(\text { eGFR } 30-60 \mathrm{~mL} / \mathrm{min} / 1.73 \mathrm{~m}^{2}\right) \\
4\left(\text { eGFR } 15-30 \mathrm{~mL} / \mathrm{min} / 1.73 \mathrm{~m}^{2}\right)\end{array}\end{array}$ & $\begin{array}{r}80(20.0 \%) \\
188(47.0 \%) \\
116(29.0 \%) \\
16(4.0 \%)\end{array}$ & $\begin{array}{r}77(19.9 \%) \\
185(47.9 \%) \\
112(29.0 \%) \\
12(3.1 \%)\end{array}$ & $\begin{array}{l}3(21.4 \%) \\
3(21.4 \%) \\
4(28.6 \%) \\
4(28.6 \%)\end{array}$ & .002 \\
\hline $\begin{array}{l}\text { Thakar score } \\
\begin{array}{l}1 \\
2 \\
3 \\
4 \\
\geq 5\end{array}\end{array}$ & $\begin{aligned} & 233(58.3 \%) \\
& 19(4.8 \%) \\
& 117(29.3 \%) \\
& 15(3.8 \%) \\
& 16(4.0 \%)\end{aligned}$ & $\begin{array}{c}230(59.6 \%) \\
19(4.9 \%) \\
112(29.0 \%) \\
14(3.6 \%) \\
11(2.8 \%)\end{array}$ & $\begin{array}{l}3(21.4 \%) \\
0(0 \%) \\
5(35.7 \%) \\
1(7.1 \%) \\
5(35.7 \%)\end{array}$ & $<.001$ \\
\hline \multicolumn{5}{|l|}{ Procedure characteristics } \\
\hline Isolated CABG & $131(32.8 \%)$ & $127(32.9 \%)$ & $4(28.6 \%)$ & .74 \\
\hline Isolated valve surgery & $168(42.0 \%)$ & $165(42.7 \%)$ & $3(21.4 \%)$ & .11 \\
\hline CABG/valve surgery & $61(15.3 \%)$ & $58(15.0 \%)$ & $3(21.4 \%)$ & .51 \\
\hline Aorta surgery & $40(10.0 \%)$ & $36(9.3 \%)$ & $4(28.5 \%)$ & .04 \\
\hline Cardiopulmonary bypass use & $283(70.8 \%)$ & $272(70.4 \%)$ & $11(78.5 \%)$ & .77 \\
\hline
\end{tabular}

Continuous variables are represented as median (25th-75th percentiles) and categorical variables as number (percent). AKI, Acute kidney injury; $C A B G$, coronary artery bypass grafting; $C V A$, cerebral vascular accident; $C O P D$, chronic obstructive pulmonary disease; $L V$, left ventricular; $A C E$, angiotensin converting enzyme; $e G F R$, estimated glomerular filtration rate; $C K D$, chronic kidney disease. 

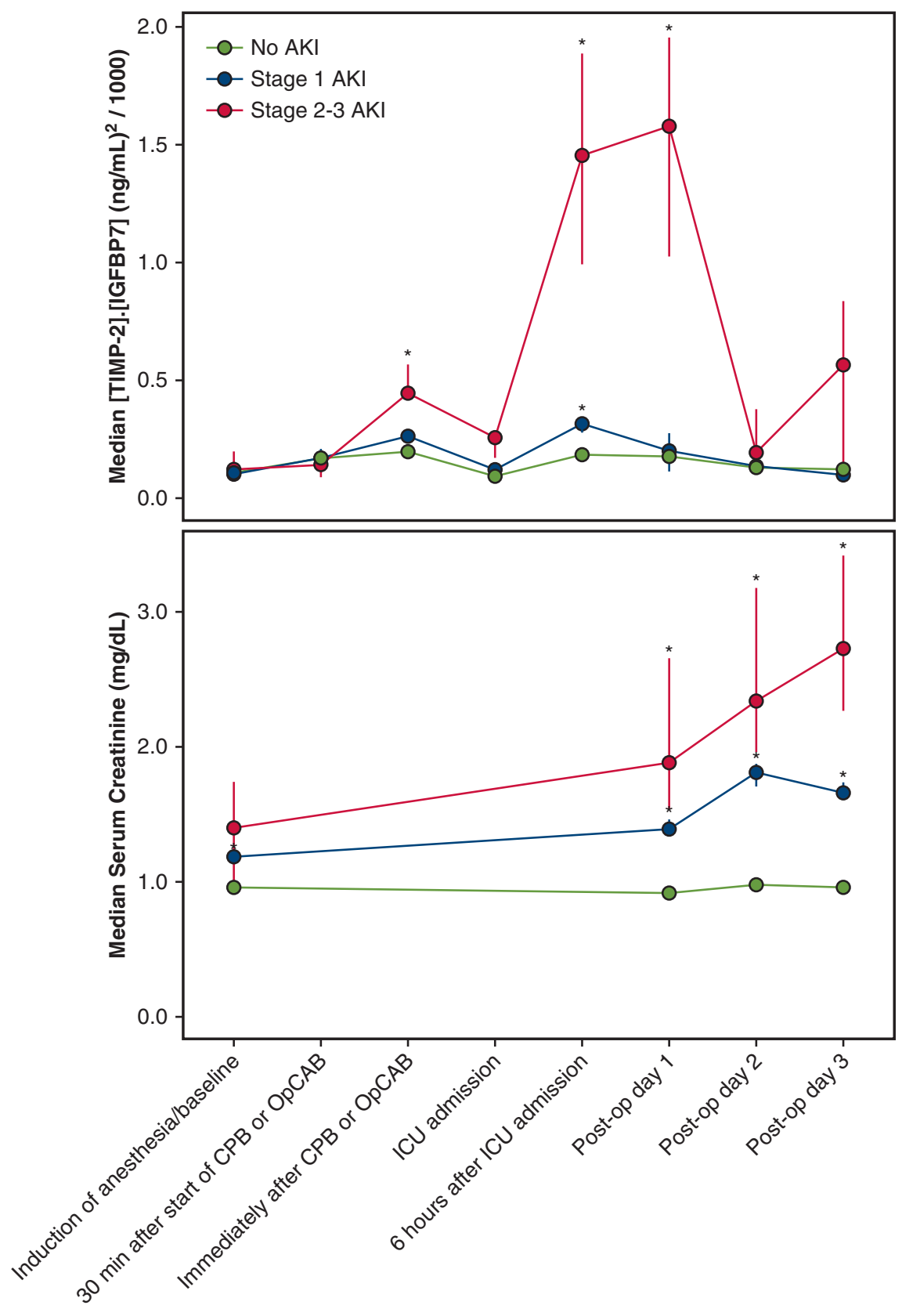

Timepoint

FIGURE 2. Median perioperative urinary [TIMP-2]·[IGFBP7] and serum creatinine concentrations in patients with no acute kidney injury (AKI; green), stage $1 \mathrm{AKI}$ (blue), and stage 2 or $3 \mathrm{AKI}$ (red). Vertical lines through the dots show the interquartile range of bootstrap medians for the [TIMP-2]· [IGFBP7] and creatinine concentrations. ${ }^{*} P<.05$ for comparing the distributions of [TIMP-2]·[IGFBP7] or creatinine values to the distributions among patients without AKI. AKI, Acute kidney injury; $C P B$, cardiopulmonary bypass; $O P C A B$, off-pump coronary artery bypass; $I C U$, intensive care unit.

increased to $0.17(0.02,0.93)$ during $\mathrm{CPB} / \mathrm{OpCAB}$, peaked at $0.22(0.04,1.58)$ following $\mathrm{CPB} / \mathrm{OpCAB}$, decreased to $0.10(0.02,0.67)$ at ICU admission, increased again to $0.21(0.04,0.84) 6$ hours after ICU admission, remained elevated at $0.19(0.02,1.34)$ on postoperative day 1 , and decreased back toward baseline by postoperative day 2 .
Patients who developed stage 2 or 3 AKI displayed a bimodal time course. Specifically, [TIMP-2]·[IGFBP7] increased significantly immediately after the end of $\mathrm{CPB}$ or OpCAB, returned toward baseline at ICU admission, and then subsequently increased considerably more 6 hours after ICU admission and remained elevated into 
TABLE 2. Unadjusted and adjusted odds ratios for development of stage 2 or 3 AKI using perioperative measurements of [TIMP-2]·[IGFBP7]

\begin{tabular}{|c|c|c|c|c|}
\hline Timepoint & Unadjusted OR (95\% CI) & $P$ value & Adjusted OR* (95\% CI) & $P$ value \\
\hline After $\mathrm{CPB}$ or OpCAB & $3.3(1.3-8.3)$ & .01 & $3.9(1.3-11.1)$ & .01 \\
\hline ICU admission & $2.7(1.2-5.7)$ & .01 & $2.5(1.1-5.6)$ & .03 \\
\hline $6 \mathrm{~h}$ after ICU admission & $11.5(3.6-37.2)$ & $<.001$ & $7.5(2.0-28.1)$ & .003 \\
\hline Postoperative day 1 & $5.4(2.2-15.1)$ & $<.001$ & $4.6(1.7-12.7)$ & .003 \\
\hline Sum of post-CPB/OpCAB and $6 \mathrm{~h}$ after ICU admission & $10.8(3.5-33.0)$ & $<.001$ & $9.4(2.6-34.2)$ & $<.001$ \\
\hline Product of post-CPB/OpCAB and $6 \mathrm{~h}$ after ICU admission & $9.9(3.3-30.0)$ & $<.001$ & $8.2(2.3-30.0)$ & .001 \\
\hline Max of post-CPB/OpCAB and $6 \mathrm{~h}$ after ICU admission & $9.6(3.2-28.7)$ & $<.001$ & $8.5(2.4-30.0)$ & $<.001$ \\
\hline Sum of all timepoints & $15.4(4.6-51.6)$ & $<.001$ & $12.6(3.2-50.0)$ & $<.001$ \\
\hline Max of all timepoints & $13.4(4.2-42.3)$ & $<.001$ & $10.9(3.0-39.3)$ & $<.001$ \\
\hline
\end{tabular}

$P$ values reflect association between [TIMP-2]·[IGFBP7] and odds of AKI at each timepoint. $O R$, Odds ratio; $C I$, confidence interval; $C P B$, cardiopulmonary bypass; $O P C A B$, off-pump coronary artery bypass; ICU, intensive care unit. *Adjusted for body mass index, Thakar score, and baseline hematocrit. [TIMP-2] [ [IGFBP7] values were $\log$-transformed in all models. As such, OR values represent the change in odds of AKI per $\log _{10}\left([T I M P-2] \cdot[I G F B P 7](n g / m L)^{2} / 1000\right)$ increase.

postoperative day 1 before decreasing toward baseline on postoperative day 2 in stage 2 or 3 AKI patients compared to patients with stage 1 or no AKI (Figure 2). Both of these [TIMP-2]·[IGFBP7] elevations occurred before serum creatinine concentrations had risen above baseline. Median [TIMP-2] [ [IGFBP7] values in the stage 2 or 3 AKI patients were $0.12,0.45,0.26,1.45$, and $1.58(\mathrm{ng} / \mathrm{mL})^{2} / 1000$ at baseline, immediately after $\mathrm{CPB} / \mathrm{OpCAB}$, ICU admission, 6 hours after ICU admission, and postoperative day 1, respectively. Patients who developed stage 1 AKI also had significantly elevated [TIMP-2]·[IGFBP7] 6 hours after ICU admission, a median concentration of $0.32(\mathrm{ng} / \mathrm{mL})^{2} / 1000$, compared to non-AKI patients and also demonstrated intraoperative postoperative bimodal urinary [TIMP-2]·[IGFBP7] peaks, but significantly less so than patients who developed stage 2 or 3 AKI. Minimal change was observed in [TIMP-2]·[IGFBP7] during and after surgery in patients who did not develop any AKI, with median [TIMP-2]·[IGFBP7] at or below $0.20(\mathrm{ng} / \mathrm{mL})^{2} / 1000$ throughout the perioperative period (Table E2). Urinary [TIMP-2]·[IGFBP7] was unaffected by perioperative atorvastatin treatment, the intervention in the randomized trial (Table E3).

Increased concentrations of intraoperative and early postoperative [TIMP-2]·[IGFBP7] were independently associated with increased AKI. The adjusted odds ratio for [TIMP-2] [IIGFBP7] to predict stage 2-3 AKI (95\% CI) was $3.9(1.3-11.1)$ post $\mathrm{CPB} / \mathrm{OpCAB}, 2.5(1.1-5.6)$ at ICU admission, 7.5 (2.0-28.0) six hours after ICU admission, and $4.6(1.7-12.7)$ on postoperative day 1 (Table 2). The reported odds ratios indicate the odds increase for developing stage 2 or 3 AKI for each $\log _{10}$ ([TIMP-2] [ [IGFBP7] $\left.(\mathrm{ng} / \mathrm{mL})^{2} / 1000\right)$ increase. Body mass index, Thakar score, and baseline hematocrit were also independently associated with stage 2 or 3 AKI in these models. There were no significant interactions among these clinical factors and the association between increasing
[TIMP-2] · [IGFBP7] and AKI (eg, increasing or decreasing Thakar score did not modify the association between [TIMP-2] $[$ IGFBP7] and AKI).

The AUROC $(95 \% \mathrm{CI})$ values for prediction of stage 2-3 AKI were 0.71 (0.58-0.82), $0.68 \quad(0.54-0.81), \quad 0.78$ (0.58-0.93), and 0.75 (0.59-0.90), respectively, for [TIMP-2]·[IGFBP7] samples collected immediately after the end of $\mathrm{CPB} / \mathrm{OpCAB}$, at ICU admission, six hours after ICU admission, and on postoperative day 1 . These results indicate that [TIMP-2]·[IGFBP7] both during and after surgery is informative for assessing risk of postoperative stage 2-3 AKI.

To explore AKI predictive capabilities using the breadth of the perioperative [TIMP-2] [IGFBP7] data, we combined data at different timepoints using addition, multiplication, and selection of maximum values of timepoints. These different methods yielded similar results to prediction using single timepoints, with AUROC estimates ranging from 0.81 to 0.82 (Table 3). The AUROC to predict stage 2 or 3 AKI using the maximum value of the [TIMP-2]·[IGFBP7] collected immediately after the end of $\mathrm{CPB} / \mathrm{OpCAB}$ and the [TIMP-2] [ [IGFBP7] collected 6 hours after ICU admission yielded the highest AUROC - a value of $0.82(95 \% \mathrm{CI}$, 0.73-0.90)—equivalent to that for the maximum of all 8 perioperative [TIMP-2] [IGFBP7] measurements, 0.82 (95\% CI, 0.72-0.91). When combined with the clinical factors used in the baseline model, the addition of the maximum [TIMP-2]-[IGFBP7] between the post-CPB/OpCAB and the 6 hours after ICU admission timepoints increased the AUROC from 0.86 (95\% CI, 0.77-0.94) to 0.90 (95\% CI, $0.82-0.96$ ), $P=.07$ (Figure E1) and led to a continuous net reclassification improvement of 0.91 (95\% CI, 0.38-1.45; $P<.001)$.

When stratified by the 0.3 and $2.0(\mathrm{ng} / \mathrm{mL})^{2} / 1000$ clinical thresholds established in other cohorts for the prediction of moderate or severe AKI, increased baseline urinary [TIMP-2]·[IGFBP7] was associated with 
TABLE 3. AUROCs for development of stage 2 or 3 AKI at different perioperative measurements of [TIMP-2]·[IGFBP7] alone, [TIMP-2] [IGFBP7] in addition to baseline clinical model factors, and the continuous NRI to predict stage 2 or 3 AKI by adding [TIMP-2]·[IGFBP7] to the baseline model

\begin{tabular}{|c|c|c|c|c|c|}
\hline Timepoint & $\begin{array}{c}\text { AUROC } \\
{[\text { TIMP-2]·[IGFBP7] }}\end{array}$ & $\begin{array}{c}\text { AUROC } \\
\text { [TIMP-2] } \\
\text { [IGFBP7] }+ \\
\text { Baseline factors }\end{array}$ & $\begin{array}{c}P \\
\text { value* }\end{array}$ & Continuous NRI & $\begin{array}{c}P \\
\text { value }\end{array}$ \\
\hline Post $\mathrm{CPB}$ or OpCAB & $0.71(0.58-0.82)$ & $0.86(0.75-0.95)$ & .93 & $0.83(0.27-1.38)$ & .003 \\
\hline ICU admission & $0.68(0.54-0.81)$ & $0.88(0.79-0.95)$ & .26 & $0.39(0.17-0.94)$ & .17 \\
\hline $6 \mathrm{~h}$ after ICU admission & $0.78(0.58-0.93)$ & $0.86(0.72-0.98)$ & .76 & $0.87(0.27-1.47)$ & .005 \\
\hline Postoperative day 1 & $0.75(0.59-0.90)$ & $0.92(0.88-0.96)$ & .19 & $0.74(0.17-1.32)$ & .01 \\
\hline Sum of post-CPB/OpCAB and $6 \mathrm{~h}$ after ICU admission & $0.81(0.74-0.90)$ & $0.90(0.82-0.96)$ & .07 & $0.91(0.38-1.45)$ & .001 \\
\hline Product of post-CPB/OpCAB and $6 \mathrm{~h}$ after ICU admission & $0.81(0.71-0.89)$ & $0.86(0.78-0.96)$ & .20 & $0.83(0.29-1.36)$ & .002 \\
\hline Maximum of post-CPB/OpCAB and $6 \mathrm{~h}$ after ICU admission & $0.82(0.73-0.90)$ & $0.90(0.82-0.96)$ & .07 & $0.91(0.38-1.45)$ & .001 \\
\hline Sum of all timepoints & $0.82(0.71-0.91)$ & $0.90(0.79-0.97)$ & .17 & $1.04(0.50-1.57)$ & $<.001$ \\
\hline Maximum of all timepoints & $0.82(0.72-0.91)$ & $0.92(0.80-0.98)$ & .05 & $1.14(0.61-1.68)$ & $<.001$ \\
\hline
\end{tabular}

$A U R O C$, Area under the receiver operating characteristic curve; $N R I$, net classification improvement; $C P B$, cardiopulmonary bypass; $O p C A B$, off-pump coronary artery bypass; $I C U$, intensive care unit. *Represent the differences between the AUROCs (95\% confidence interval) of the baseline model [0.86 (0.77-0.94)] and the model that includes [TIMP2]-[IGFBP7] and baseline factors.

in-hospital dialysis and death (Table E4). Patients with elevated urinary [TIMP-2]·[IGFBP7] 6 hours after ICU admission also had more in-hospital dialysis $(P<.001)$ and a longer ICU length of stay $(P=.006)$. [TIMP-2] [IGFBP7] immediately after the end of CPB/OpCAB and 6 hours after ICU admission was predictive of stage 2 or 3 AKI, consistent with the agnostic approach that did not use 0.3 or 2.0 clinical thresholds. In addition, use of the maximum value of the post-CPB/OpCAB measurement and the 6-hour ICU measurement with the 0.3 clinical threshold yielded $100 \%$ sensitivity for prediction of AKI, compared with $85 \%$ and $73 \%$ sensitivity using the individual post $\mathrm{CPB} / \mathrm{OpCAB}$ and the 6-hour ICU individual timepoints, respectively (Table E5). The incidence of not having AKI with a [TIMP-2]·[IGFBP7] less than the 0.3 threshold was $99 \%$ at both the post-CPB/OpCAB and the 6-hour ICU timepoints and $100 \%$ when using the maximum of these two timepoints (100\% negative predictive value). The specificity of [TIMP-2] [IGFBP7] to predict AKI using the 0.3 threshold was lower $(62 \%$ when using the value post-CPB/OpCAB and $64 \% 6$ hours after ICU) but $93 \%$ and $98 \%$, respectively, when using the 2.0 threshold.

Analysis of the 283-patient subgroup who received surgery with CPB $(70.8 \%$ of the total cohort) yielded similar results to the analysis of the total cohort. Eleven of the 283 patients $(3.9 \%$ ) developed stage 2 or 3 (moderate or severe) AKI. These patients displayed bimodal elevations of [TIMP-2] · [IGFBP7], with a first elevation (median $0.57[\mathrm{ng} / \mathrm{mL}]^{2} / 1000$ ) occurring intraoperatively following $\mathrm{CPB}$ and the second elevation $\left(1.22[\mathrm{ng} / \mathrm{mL}]^{2} / 1000\right) 6$ hours postoperatively. Patients with $\mathrm{CPB}$ who did not develop AKI did not have any elevations in [TIMP-2] [IGFBP7]. Each 10-fold increase in intraoperative [TIMP-2]. [IGFBP7] was independently associated with a $433 \%$ increase in the odds of stage 2 or 3 AKI $(P=.01)$, and each 10-fold increase in 6-hour postoperative [TIMP-2]. [IGFBP7] was associated with a $319 \%$ increase in the odds of stage 2 or 3 AKI $(P=.07)$. The maximum [TIMP-2] - [IGFBP7] between the intraoperative and the 6hour postoperative timepoints provided an AUROC of 0.81 (95\% CI, 0.71-0.90), 100\% sensitivity, and 100\% negative predictive value using the $>0.3$ cutoff to predict stage 2 or 3 AKI, similar to the 0.82 (95\% CI, 0.72-0.90) AUROC, $100 \%$ sensitivity, and $100 \%$ NPV metrics from the entire cohort (Video 1).

\section{DISCUSSION}

In this study we observed that increased intraoperative concentrations and increased early postoperative concentrations of [TIMP-2] [IGFBP7] are independently associated with development of moderate or severe AKI and that perioperative [TIMP-2]·[IGFBP7] is a highly sensitive predictor of postoperative AKI. During surgery, patients at high risk for AKI can be identified and therefore can be given specific treatment or selected for testing novel interventions.

The current study also provides the most granular characterization of the time-course of [TIMP-2] · [IGFBP7] in patients at typical risk of AKI after heart surgery. We report an initial urinary [TIMP-2]·[IGFBP7] increase during surgery followed by a decrease at ICU admission and then a sharp increase within 6 hours in patients who later received a diagnosis of stage 2 or 3 AKI. This bimodal elevation of [TIMP-2]·[IGFBP7], also reported in a pilot study be Mayer and colleagues, ${ }^{25}$ may be important. It is consistent with the concept that CSA-AKI results from both intraoperative and postoperative insults. This transient reduction at ICU admission in AKI patients could reflect 
decreased kidney stress following termination of $\mathrm{CPB}$, post$\mathrm{CPB}$ resuscitation, and hemodynamic optimization before further renal insults occur in the early postoperative period. Alternatively, this transient reduction could reflect changes in glomerular filtration that alter urine creatinine or urine dilution. From an AKI prediction standpoint, the sensitivity of intraoperative [TIMP-2] [IGFBP7] to predict AKI was limited by misclassification of patients who suffer a renal insult later in surgery as low risk. A test cannot detect an insult that has not yet occurred. Conversely, the use of only postoperative data misclassified different patients-those who had suffered intraoperative renal injury-as low risk. When using the maximum of the post-CPB/OpCAB intraoperative measurement and the 6 hours after ICU measurement, however, both intraoperative and early postoperative renal stress have occurred. In the current study, all patients with AKI were identified $(100 \%$ sensitivity). These data suggest that elevated intraoperative and early postoperative urinary [TIMP-2]·[IGFBP7] can effectively identify patients undergoing acute kidney stress and provide opportunities for intervention. We examined the perioperative course of the patients who developed moderate or severe AKI to identify additional clinical characteristics that could account for the bimodal [TIMP-2] [IGFBP7] peak in these patients. We did not discover a specific pattern in patients who developed moderate or severe AKI, although these patients had a lower hematocrit post-CPB/OpCAB, received more packed red blood cell transfusions during surgery, and received higher doses of norepinephrine in the early postoperative period than patients who did not develop moderate or severe AKI. Use and duration of aortic cross-clamp, intraoperative cardiac output, intraoperative blood pressure, and intraoperative doses of norepinephrine, however, were similar between patients who did and did not develop moderate or severe AKI.

Meersch and colleagues ${ }^{26}$ randomized patients identified as high-risk for CSA-AKI, defined as [TIMP-2]. [IGFBP7] $>0.3(\mathrm{ng} / \mathrm{mL})^{2} / 1000$ four hours after termination of CPB, to early intervention with the KDIGO bundle, primarily hemodynamic and volume optimization and avoidance of toxins or renal stressors, versus standard care and showed a significant decrease in the subsequent rates of moderate or severe AKI. ${ }^{26}$ Gocze and colleagues, ${ }^{16}$ in a similar study of major noncardiac surgery patients, showed that early application of the KDIGO bundle in patients with [TIMP-2] [IGFBP7] $>0.3(\mathrm{ng} / \mathrm{mL})^{2} / 1000$ also resulted in decreased rates of moderate or severe AKI, decreased ICU and hospital length of stay, and decreased cost. ${ }^{16}$

Use of [TIMP-2] [IGFBP7] in clinical practice remains limited, in part because of uncertainty about how and when to use the test. As initially demonstrated by Hoste and colleagues, ${ }^{18}$ a $0.3(\mathrm{ng} / \mathrm{mL})^{2} / 1000$ cutoff for [TIMP2]·[IGFBP7] provides early recognition with high

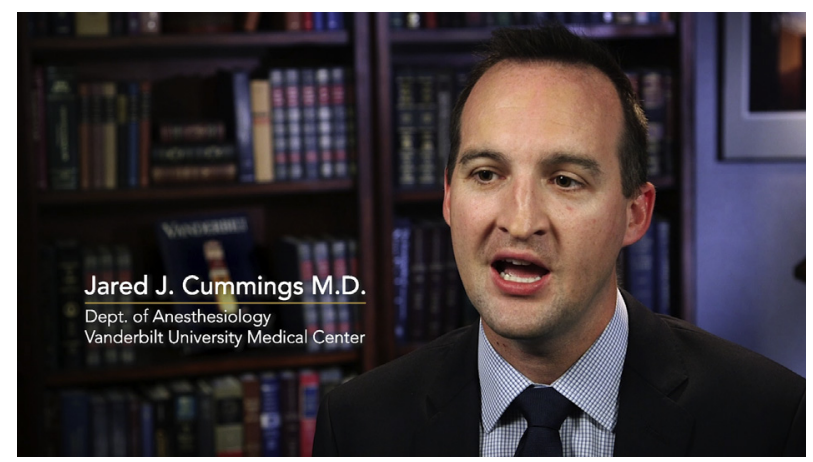

VIDEO 1. Dr. Jared J. Cummings discusses the rationale for the project, the principal findings, and the relevance of these findings to readers of the Journal. Video available at: https://www.jtcvs.org/article/S00225223(18)32484-X/fulltext.

sensitivity for development of AKI in adult patients in the ICU. ${ }^{18}$ This 0.3 cutoff was further validated in another cohort of ICU patients and also among adults undergoing cardiac surgery. ${ }^{14,15,25,27,28}$ Given the time-course of [TIMP-2]·[IGFBP7] seen in our study, we propose measuring [TIMP-2] ·[IGFBP7] immediately after termination of CPB and, if it is $<0.3$, again at 4 to 6 hours after ICU admission. If either the intraoperative or the early postoperative [TIMP-2] $\left[\right.$ IGFBP7] is $>0.3(\mathrm{ng} / \mathrm{mL})^{2} / 1000$, we recommend instituting renal supportive measures such as the KDIGO bundle, as demonstrated by Meersch and colleagues, ${ }^{15}$ and additional vigilance to patient monitoring. If neither the intraoperative nor the early postoperative tests are positive $\left(>0.3[\mathrm{ng} / \mathrm{mL}]^{2} / 1000\right)$, the treating clinician can be confident that the patient will not develop stage 2 or 3 AKI (the "double-negative" [TIMP-2]·[IGFBP7]). Indeed, the negative predictive value of using this sampling strategy in the current study was $100 \%$. Measurement at additional perioperative timepoints did not confer additional benefit for predicting AKI, nor did combining the amplitude of the intraoperative and early postoperative measurements by computing their sum or product. This sampling strategy is consistent with studies demonstrating that the maximum value of [TIMP-2]. [IGFBP7] during the first 24 hours outperforms individual timepoint data values. ${ }^{14}$ [TIMP-2]·[IGFBP7] after $\mathrm{CPB} / \mathrm{OpCAB}$ and 6 hours after ICU admission identified all patients who would subsequently develop moderate or severe AKI. An intraoperative and early postoperative sampling scheme can therefore adequately capture relevant renal stress, provide good opportunity for early intervention, and allow clinicians to identify low-risk patients, thereby maximizing resources and attention.

We acknowledge several limitations to this study. Foremost, although consistent with many cardiac surgery cohorts, the rate of stage 2 or 3 AKI was low. The use of urine output criteria to identify additional patients who might have developed stage 2 or 3 AKI could have added 
additional valuable data. However, the use of urine output to diagnose AKI following cardiac surgery is controversial because of confounding by intravascular hypovolemia and diuretic administration, and the separation of [TIMP-2]. [IGFBP7] between patients who developed stage 2 or 3 AKI and those who developed stage 1 or no AKI using creatinine data was striking. The study was completed at a single center, and results could be different elsewhere. More data from additional medical centers and patient populations are needed. Nonetheless, this is the largest and most granular urinary [TIMP-2]·[IGFBP7] cardiac surgery study to date, and it is further strengthened by the rigorous phenotyping of the Statin AKI Cardiac Surgery RCT cohort.

In conclusion, intraoperative elevations of [TIMP-2] [IGFBP7] were independently associated with development of stage 2 or 3 CSA-AKI and an intraoperative and early postoperative 2-measurement sampling scheme provided excellent ability to detect both patients who would and those who would not develop CSA-AKI. Larger trials should be conducted to characterize any reductions in major adverse kidney events or costs from measuring [TIMP-2] [IGFBP7] to identify patients who will and will not develop CSA-AKI.

\section{Conflict of Interest Statement}

A.D.S. and J.S. are consultants for Astute Medical, which developed the [TIMP-2]·[IGFBP7] NephroCheck assay and performed urinary [TIMP-2] [IGFBP7] measurements blinded to all subject characteristics. Astute Medical did not participate in the design of the study or decision to submit the findings for publication. J.S. completed the statistical analysis. J.J.C., A.D.S., J.S., and F.T.B. wrote the manuscript. All other authors have nothing to disclose with regard to commercial support.

We acknowledge Patty Hendricks, RN, for nursing support and Astute Medical for blinded measurements of [TIMP-2]. [IGFBP7].

\section{References}

1. Hu J, Chen R, Liu S, Yu X, Zou J, Ding X. Global incidence and outcomes of adult patients with acute kidney injury after cardiac surgery: a systematic review and meta-analysis. J Cardiothorac Vasc Anesth. 2016;30:82-9.

2. Fuhrman DY, Kellum JA. Epidemiology and pathophysiology of cardiac surgery-associated acute kidney injury. Curr Opin Anaesthesiol. 2017;30:60-5.

3. D'Agostino RS, Jacobs JP, Badhwar V, Fernandez FG, Paone G, Wormuth DW, et al. The Society of Thoracic Surgeons adult cardiac surgery database: 2018 update on outcomes and quality. Ann Thorac Surg. 2018;105:15-23.

4. Wang Y, Bellomo R. Cardiac surgery-associated acute kidney injury: risk factors, pathophysiology and treatment. Nat Rev Nephrol. 2017;13:697-711.

5. Zakkar M, Bruno VD, Guida G, Angelini GD, Chivasso P, Suleiman MS, et al. Postoperative acute kidney injury defined by RIFLE criteria predicts early health outcome and long-term survival in patients undergoing redo coronary artery bypass graft surgery. J Thorac Cardiovasc Surg. 2016;152:235-42.

6. O'Neal JB, Shaw AD, FTt Billings. Acute kidney injury following cardiac surgery: current understanding and future directions. Crit Care. 2016;20:187.
7. Bellomo R, Kellum JA, Ronco C. Defining acute renal failure: physiological principles. Intensive Care Med. 2004;30:33-7.

8. Albert C, Albert A, Kube J, Bellomo R, Wettersten N, Kuppe H, et al. Urinary biomarkers may provide prognostic information for subclinical acute kidney injury after cardiac surgery. J Thorac Cardiovasc Surg. 2018;155: 2441-52.e2413.

9. Koyner JL, Bennett MR, Worcester EM, Ma Q, Raman J, Jeevanandam V, et al. Urinary cystatin $\mathrm{C}$ as an early biomarker of acute kidney injury following adult cardiothoracic surgery. Kidney Int. 2008;74:1059-69.

10. Han WK, Wagener G, Zhu Y, Wang S, Lee HT. Urinary biomarkers in the early detection of acute kidney injury after cardiac surgery. Clin J Am Soc Nephrol. 2009;4:873-82.

11. Kashani K, Al-Khafaji A, Ardiles T, Artigas A, Bagshaw SM, Bell M, et al Discovery and validation of cell cycle arrest biomarkers in human acute kidney injury. Crit Care. 2013;17:R25.

12. Schrezenmeier EV, Barasch J, Budde K, Westhoff T, Schmidt-Ott KM Biomarkers in acute kidney injury - pathophysiological basis and clinical performance. Acta Physiol (Oxf). 2017;219:554-72.

13. Khwaja A. KDIGO clinical practice guidelines for acute kidney injury. Nephron Clin Pract. 2012;120:c179-84.

14. Pilarczyk K, Edayadiyil-Dudasova M, Wendt D, Demircioglu E, Benedik J, Dohle DS, et al. Urinary [TIMP-2]*[IGFBP7] for early prediction of acute kidney injury after coronary artery bypass surgery. Ann Intensive Care. 2015; 5:50.

15. Meersch M, Schmidt C, Van Aken H, Martens S, Rossaint J, Singbartl K, et al Urinary TIMP-2 and IGFBP7 as early biomarkers of acute kidney injury and renal recovery following cardiac surgery. PLoS One. 2014;9:e93460.

16. Gocze I, Jauch D, Gotz M, Kennedy P, Jung B, Zeman F, et al. Biomarker-guided intervention to prevent acute kidney injury after major surgery: the prospective randomized BigpAK study. Ann Surg. 2017;267:1013-20.

17. Gocze I, Koch M, Renner P, Zeman F, Graf BM, Dahlke MH, et al. Urinary biomarkers TIMP-2 and IGFBP7 early predict acute kidney injury after major surgery. PLoS One. 2015;10:e0120863.

18. Hoste EA, McCullough PA, Kashani K, Chawla LS, Joannidis M, Shaw AD, et al Derivation and validation of cutoffs for clinical use of cell cycle arrest biomarkers. Nephrol Dial Transplant. 2014;29:2054-61.

19. FTt Billings, Pretorius M, Schildcrout JS, Mercaldo ND, Byrne JG, Ikizler TA, et al. Obesity and oxidative stress predict AKI after cardiac surgery. J Am Soc Nephrol. 2012;23:1221-8.

20. Billings FT, Ball SK, Roberts LJ II, Pretorius M. Postoperative acute kidney injury is associated with hemoglobinemia and an enhanced oxidative stress response. Free Radic Biol Med. 2011;50:1480-7.

21. Billings FT, Hendricks PA, Schildcrout JS, Shi Y, Petracek MR, Byrne JG, et al High-dose perioperative atorvastatin and acute kidney injury following cardiac surgery: a randomized clinical trial. JAMA. 2016;315:877-88.

22. Thakar CV, Arrigain S, Worley S, Yared JP, Paganini EP. A clinical score to predict acute renal failure after cardiac surgery. J Am Soc Nephrol. 2005;16:162-8.

23. Robin X, Turck N, Hainard A, Tiberti N, Lisacek F, Sanchez JC, et al. pROC: an open-source package for $\mathrm{R}$ and $\mathrm{S}+$ to analyze and compare ROC curves. $B M C$ Bioinformatics. 2011;12:77.

24. R Core Team. R: A Language and Environment for Statistical Computing. Vienna, Austria: R Foundation for Statistical Computing; 2014.

25. Mayer T, Bolliger D, Scholz M, Reuthebuch O, Gregor M, Meier P, et al. Urine biomarkers of tubular renal cell damage for the prediction of acute kidney injury after cardiac surgery—a pilot study. J Cardiothorac Vasc Anesth. 2017; 31:2072-9.

26. Meersch M, Schmidt C, Hoffmeier A, Van Aken H, Wempe C, Gerss J, et al Prevention of cardiac surgery-associated AKI by implementing the KDIGO guidelines in high risk patients identified by biomarkers: the PrevAKI randomized controlled trial. Intensive Care Med. 2017;43:1749.

27. Wang Y, Zou Z, Jin J, Teng J, Xu J, Shen B, et al. Urinary TIMP-2 and IGFBP7 for the prediction of acute kidney injury following cardiac surgery. BMC Nephrol. 2017;18:177.

28. Bihorac A, Chawla LS, Shaw AD, Al-Khafaji A, Davison DL, Demuth GE, et al Validation of cell-cycle arrest biomarkers for acute kidney injury using clinical adjudication. Am J Respir Crit Care Med. 2014;189:932-9.

Key Words: acute kidney injury, cardiac surgery, biomarker, TIMP-2, IGFBP7, NephroCheck, prediction 


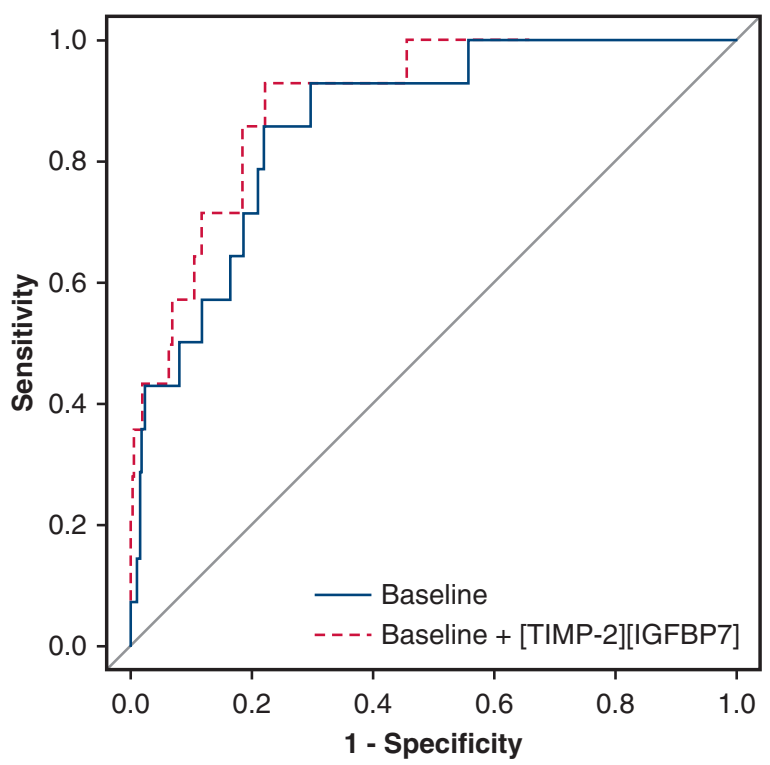

FIGURE E1. Area under the receiver operating characteristic (AUROC) curves for the baseline clinical model (AUROC $=0.86 ; 95 \%$ confidence interval [CI], 0.77-0.94) and the model that includes the maximum of the post-cardiopulmonary bypass/OpCAB timepoint and the 6 hours after ICU admission timepoint, in addition to baseline clinical factors $($ AUROC $=0.90 ; 95 \%$ CI, 0.82-0.96). 
TABLE E1. Distributions of candidate clinical variables for multivariable regression

\begin{tabular}{|c|c|c|c|c|}
\hline & $\frac{\text { All }}{(\mathbf{N}=\mathbf{4 0 0})}$ & $\frac{\text { No AKI or Stage } 1}{(\mathbf{N}=\mathbf{3 8 6})}$ & $\frac{\text { Stage } 2 \text { or } 3}{(N=14)}$ & $P$ value \\
\hline Age (y) & & & & .04 \\
\hline Mean (SD) & $65.8(12.7)$ & $66.1(12.7)$ & $59.1(12.8)$ & \\
\hline Median & 67 & 67 & 59 & \\
\hline IQR & 23.92 & 58.75 & $51.2,69$ & \\
\hline Female & $131(33 \%)$ & $125(32 \%)$ & $6(43 \%)$ & .40 \\
\hline \multicolumn{5}{|l|}{ Medical history } \\
\hline $\mathrm{CHF}$ & $163(40.8 \%)$ & $156(40.4 \%)$ & $7(50.0 \%)$ & .58 \\
\hline Current smoker & $67(16.8 \%)$ & $66(17.1 \%)$ & $1(7.1 \%)$ & .48 \\
\hline Diabetes mellitus & $123(30.8 \%)$ & $120(31.1 \%)$ & $3(21.4 \%)$ & .56 \\
\hline Cardiac surgery & $74(18.5 \%)$ & $69(17.9 \%)$ & $5(35.7 \%)$ & .15 \\
\hline Cardiac catheterization & $148(37.0 \%)$ & $144(37.3 \%)$ & $4(28.6 \%)$ & .59 \\
\hline BMI $\left(\mathrm{kg} / \mathrm{m}^{2}\right)$ & & & & .10 \\
\hline Mean (SD) & $28.5(6.1)$ & $28.4(5.9)$ & $33.2(9.9)$ & \\
\hline Median & 27.4 & 27.3 & 31.7 & \\
\hline IQR & $15.2-54.1$ & $24.7-31$ & $23.9-39.3$ & \\
\hline Charlson Comorbidity Index & & & & .12 \\
\hline Mean (SD) & $2.4(1.9)$ & $2.4(1.9)$ & $3.1(2)$ & \\
\hline Median & 2 & 2 & 4 & \\
\hline IQR & $0-9$ & $1-4$ & $1-4.8$ & \\
\hline Baseline serum creatinine $(\mathrm{mg} / \mathrm{dL})$ & & & & .14 \\
\hline Mean (SD) & $1.1(0.5)$ & $1.1(0.4)$ & $1.8(1.2)$ & \\
\hline Median & 1 & 1 & 1.4 & \\
\hline IQR & $0.5,4.4$ & $0.8,1.2$ & $0.8,2.8$ & \\
\hline Baseline eGFR $\left(\mathrm{mL} / \mathrm{min} / 1.73 \mathrm{~m}^{2}\right)$ & & & & .08 \\
\hline Mean (SD) & $70.2(22.8)$ & $70.7(22)$ & $56.6(37.1)$ & \\
\hline Median & 72.3 & 72.9 & 45.8 & \\
\hline IQR & $11.6-123.2$ & $54.3-87.9$ & $22.9-83.2$ & \\
\hline CKD stage & & & & .07 \\
\hline Mean (SD) & $2.2(0.8)$ & $2.2(0.8)$ & $2.6(1.2)$ & \\
\hline Median & 2 & 2 & 3 & \\
\hline IQR & $1-4$ & $2-3$ & $2-3.8$ & \\
\hline Thakar score & & & & $<.001$ \\
\hline Mean (SD) & $1.9(1.3)$ & $1.9(1.2)$ & $3.7(2)$ & \\
\hline Median & 1 & 1 & 3 & \\
\hline IQR & $1-6$ & $1-3$ & $3-6$ & \\
\hline Baseline hematocrit $(\%)$ & & & & $<.001$ \\
\hline Mean (SD) & $39.3(5)$ & $39.5(4.9)$ & $34(5.8)$ & \\
\hline Median & 40 & 40 & 33.5 & \\
\hline IQR & $26-52$ & $37-43$ & $31-36.8$ & \\
\hline \multicolumn{5}{|l|}{ Procedure characteristics } \\
\hline Isolated CABG & $131(32.8 \%)$ & $127(32.9 \%)$ & $4(28.6 \%)$ & .74 \\
\hline Isolated valve surgery & $168(42.0 \%)$ & $165(42.7 \%)$ & $3(21.4 \%)$ & .11 \\
\hline CABG/valve surgery & $61(15.3 \%)$ & $58(15.0 \%)$ & $3(21.4 \%)$ & .51 \\
\hline Aorta surgery & $40(10.0 \%)$ & $36(9.3 \%)$ & $4(28.6 \%)$ & .04 \\
\hline $\mathrm{CPB}$ use & $283(70.8 \%)$ & $272(70.5 \%)$ & $11(78.6 \%)$ & .77 \\
\hline
\end{tabular}

$A K I$, Acute kidney injury; $S D$, standard deviation; $I Q R$, interquartile ratio; $C H F$, congestive heart failure; $B M I$, body mass index; $e G F R$, estimated glomerular filtration rate; $C K D$, chronic kidney disease; $C A B G$, coronary artery bypass grafting; $C P B$, cardiopulmonary bypass. 
TABLE E2. Perioperative 10th, 25th, 50th (median), 75th, and 90th percentiles of [TIMP-2] [ [IGFBP7] and percentages of patients greater than the 0.3 and 2.0 thresholds. $P$ values represent [TIMP-2] [IGFBP7] distribution comparisons against No AKI patients using the Conover test

\begin{tabular}{|c|c|c|c|c|c|c|c|c|c|c|}
\hline AKI & Timepoint & $\mathbf{n}$ & $10 \%$ & $25 \%$ & $\mathbf{5 0} \%$ & $\mathbf{7 5} \%$ & $90 \%$ & $>0.3$ & $>\mathbf{2 . 0}$ & $P$ value \\
\hline No AKI & Induction of anesthesia & 309 & 0.02 & 0.04 & 0.11 & 0.28 & 0.58 & $24 \%$ & $3 \%$ & \\
\hline No AKI & 30 minutes after start of $\mathrm{CPB}$ or $\mathrm{OpCAB}$ & 309 & 0.02 & 0.06 & 0.17 & 0.41 & 0.86 & $33 \%$ & $3 \%$ & \\
\hline No AKI & Immediately after end of $\mathrm{CPB}$ or $\mathrm{OpCAB}$ & 309 & 0.04 & 0.08 & 0.20 & 0.57 & 1.50 & $37 \%$ & $6 \%$ & \\
\hline No AKI & ICU admission & 309 & 0.02 & 0.04 & 0.10 & 0.23 & 0.51 & $20 \%$ & $3 \%$ & \\
\hline No AKI & Six hours after ICU admission & 309 & 0.03 & 0.09 & 0.18 & 0.38 & 0.68 & $33 \%$ & $1 \%$ & \\
\hline No AKI & Postoperative day 1 & 309 & 0.02 & 0.05 & 0.18 & 0.42 & 1.18 & $31 \%$ & $5 \%$ & \\
\hline No AKI & Postoperative day 2 & 309 & 0.03 & 0.05 & 0.13 & 0.31 & 0.81 & $29 \%$ & $2 \%$ & \\
\hline No AKI & Postoperative day 3 & 309 & 0.03 & 0.05 & 0.12 & 0.29 & 0.53 & $24 \%$ & $1 \%$ & \\
\hline Stage 1 AKI & Induction of anesthesia & 77 & 0.02 & 0.03 & 0.11 & 0.26 & 0.74 & $21 \%$ & $3 \%$ & 1.00 \\
\hline Stage 1 AKI & 30 minutes after start of $\mathrm{CPB}$ or $\mathrm{OpCAB}$ & 77 & 0.02 & 0.06 & 0.17 & 0.35 & 1.32 & $33 \%$ & $6 \%$ & 1.00 \\
\hline Stage 1 AKI & Immediately after end of $\mathrm{CPB}$ or $\mathrm{OpCAB}$ & 77 & 0.06 & 0.10 & 0.26 & 0.58 & 1.79 & $43 \%$ & $10 \%$ & .17 \\
\hline Stage 1 AKI & ICU admission & 77 & 0.03 & 0.06 & 0.12 & 0.43 & 0.83 & $28 \%$ & $6 \%$ & .09 \\
\hline Stage 1 AKI & Six hours after ICU admission & 77 & 0.04 & 0.17 & 0.32 & 0.62 & 1.16 & $51 \%$ & $7 \%$ & .01 \\
\hline Stage 1 AKI & Postoperative day 1 & 77 & 0.02 & 0.05 & 0.18 & 0.82 & 1.97 & $43 \%$ & $10 \%$ & .35 \\
\hline Stage 1 AKI & Postoperative day 2 & 77 & 0.02 & 0.05 & 0.14 & 0.46 & 1.24 & $35 \%$ & $6 \%$ & .40 \\
\hline Stage 1 AKI & Postoperative day 3 & 77 & 0.03 & 0.05 & 0.10 & 0.28 & 0.58 & $24 \%$ & $2 \%$ & .97 \\
\hline Stage 2 or $3 \mathrm{AKI}$ & Induction of anesthesia & 14 & 0.02 & 0.04 & 0.12 & 0.28 & 3.84 & $21 \%$ & $14 \%$ & 1.00 \\
\hline Stage 2 or 3 AKI & 30 minutes after start of $\mathrm{CPB}$ or $\mathrm{OpCAB}$ & 14 & 0.03 & 0.07 & 0.14 & 0.24 & 1.28 & $21 \%$ & $7 \%$ & 1.00 \\
\hline Stage 2 or 3 AKI & Immediately after end of $\mathrm{CPB}$ or OpCAB & 14 & 0.18 & 0.42 & 0.45 & 0.87 & 3.66 & $85 \%$ & $15 \%$ & .02 \\
\hline Stage 2 or $3 \mathrm{AKI}$ & ICU admission & 14 & 0.08 & 0.12 & 0.26 & 0.33 & 1.03 & $31 \%$ & $8 \%$ & .06 \\
\hline Stage 2 or 3 AKI & Six hours after ICU admission & 14 & 0.11 & 0.56 & 1.45 & 2.20 & 10.08 & $73 \%$ & $27 \%$ & .002 \\
\hline Stage 2 or 3 AKI & Postoperative day 1 & 14 & 0.05 & 0.21 & 1.58 & 2.13 & 9.13 & $67 \%$ & $33 \%$ & .006 \\
\hline Stage 2 or 3 AKI & Postoperative day 2 & 14 & 0.07 & 0.09 & 0.20 & 1.83 & 9.29 & $46 \%$ & $23 \%$ & .19 \\
\hline Stage 2 or 3 AKI & Postoperative day 3 & 14 & 0.05 & 0.06 & 0.57 & 1.33 & 13.49 & $56 \%$ & $11 \%$ & .37 \\
\hline
\end{tabular}

TABLE E3. Effect of atorvastatin administration on $\log _{10}([$ TIMP-2] $[$ [IGFBP7]) levels at each timepoint

\begin{tabular}{lcc}
\hline \multicolumn{1}{c}{ Timepoint } & Estimate $(\mathbf{9 5} \%$ confidence interval) & $\boldsymbol{P}$ value \\
\hline Induction of anesthesia (baseline) & $0.06(-0.06$ to 0.18$)$ & .34 \\
30 minutes after start of CPB or OpCAB & $0.05(-0.08$ to 0.17$)$ & .47 \\
Immediately after CPB or OpCAB & $-0.05(-0.17$ to 0.07$)$ & .43 \\
ICU admission & $-0.05(-0.17$ to 0.07$)$ & .41 \\
6 h after ICU admission & $0.03(-0.09$ to 0.13$)$ & .57 \\
Postoperative day 1 & $-0.09(-0.23$ to 0.05$)$ & .23 \\
Postoperative day 2 & $0.09(-0.04$ to 0.22$)$ & .17 \\
Postoperative day 3 & $0.03(-0.10$ to 0.16$)$ & .64 \\
\hline
\end{tabular}

Estimates calculated by linear regression. $P$ values represent the effect of atorvastatin treatment on [TIMP-2]·[IGFBP7] at each timepoint. $C B P$, Cardiopulmonary bypass; $O p C A B$, off-pump coronary artery bypass; $I C U$, intensive care unit. 
TABLE E4. In-hospital outcomes in all patients and those with [TIMP-2] [IGFBP7] concentrations $\leq \mathbf{0 . 3},>\mathbf{0 . 3}$ to $\leq \mathbf{2 . 0}$, and $>\mathbf{2 . 0}(\mathrm{ng} / \mathrm{mL})^{2} / 1000$ at induction of anesthesia, immediately after CPB or OpCAB, at ICU admission, and 6 hours after ICU admission

\begin{tabular}{|c|c|c|c|c|c|}
\hline \multirow[b]{2}{*}{ Results } & \multirow[b]{2}{*}{ All } & \multicolumn{3}{|c|}{ [TIMP-2]·[IGFBP7] } & \multirow[b]{2}{*}{$P$ value } \\
\hline & & $\leq \mathbf{0 . 3}$ & $>0.3$ to $\leq 2.0$ & $>2.0$ & \\
\hline \multicolumn{6}{|l|}{ At induction } \\
\hline $\mathrm{N}$ & 390 & 299 & 78 & 13 & - \\
\hline ICU LOS, $d$ & $3(2-24)$ & $3(2-5)$ & $3(2-5)$ & $4(3-6.5)$ & .31 \\
\hline Hospital LOS, d & $8(4-38)$ & $7(6-9)$ & $8(6-9)$ & $8.5(6.8-9)$ & .61 \\
\hline ICU readmission & $16(4.0 \%)$ & $13(4.3 \%)$ & $3(3.8 \%)$ & $0(0 \%)$ & 1.00 \\
\hline Stage 2 or $3 \mathrm{AKI}^{*}$ & $14(3.5 \%)$ & $11(3.7 \%)$ & $1(1.3 \%)$ & $2(15.4 \%)$ & .06 \\
\hline Dialysis & $7(1.8 \%)$ & $4(1.3 \%)$ & $1(1.3 \%)$ & $2(15.4 \%)$ & .03 \\
\hline Death & $5(1.2 \%)$ & $3(1 \%)$ & $0(0 \%)$ & $2(15.4 \%)$ & .01 \\
\hline \multicolumn{6}{|l|}{ After $\mathrm{CPB}$ or OpCAB } \\
\hline $\mathrm{N}$ & 382 & 231 & 123 & 28 & - \\
\hline ICU LOS, d & $3(2-24)$ & $3(2-5)$ & $3(2-5)$ & $4(2.8-5)$ & .84 \\
\hline Hospital LOS, d & $7(4-38)$ & $8(6-10)$ & $7(6-9)$ & $7(6-8.2)$ & .41 \\
\hline ICU readmission & $16(4 \%)$ & $10(4.3 \%)$ & $4(3.3 \%)$ & $1(3.6 \%)$ & .91 \\
\hline Stage 2 or $3 \mathrm{AKI}^{*}$ & $14(3.5 \%)$ & $2(0.9 \%)$ & $9(7.3 \%)$ & $2(7.1 \%)$ & .002 \\
\hline Dialysis & $7(1.8 \%)$ & $1(0.4 \%)$ & $4(3.3 \%)$ & $1(3.6 \%)$ & .05 \\
\hline Death & $5(1.2 \%)$ & $1(0.4 \%)$ & $1(0.8 \%)$ & $1(3.6 \%)$ & .24 \\
\hline \multicolumn{6}{|l|}{ On ICU admission } \\
\hline $\mathrm{N}$ & 391 & 305 & 73 & 13 & - \\
\hline ICU LOS, d & $3(2-24)$ & $3(2-5)$ & $4(2-5)$ & $3(3-5)$ & .65 \\
\hline Hospital LOS, d & $7(4-38)$ & $8(6-9)$ & $7(6-9)$ & $8(7-9)$ & .86 \\
\hline ICU readmission & $16(4.0 \%)$ & $14(4.6 \%)$ & $2(2.7 \%)$ & $0(0.0 \%)$ & .85 \\
\hline Stage 2 or $3 \mathrm{AKI}^{*}$ & $14(3.5 \%)$ & $9(3 \%)$ & $3(4.1 \%)$ & $1(7.7 \%)$ & .37 \\
\hline Dialysis & $7(1.8 \%)$ & $3(1 \%)$ & $1(1.4 \%)$ & $1(7.7 \%)$ & .14 \\
\hline Death & $5(1.2 \%)$ & $2(0.7 \%)$ & $0(0 \%)$ & $1(7.7 \%)$ & .10 \\
\hline \multicolumn{6}{|l|}{$6 \mathrm{~h}$ after ICU admission } \\
\hline $\mathrm{N}$ & 357 & 223 & 124 & 10 & - \\
\hline ICU LOS, d & $3(2-21)$ & $3(2-4.8)$ & $4(3-5)$ & $5(4.2-6.8)$ & .006 \\
\hline Hospital LOS, d & $7.5(4-38)$ & $7(6-9)$ & $8(6-9)$ & $8.5(7-11.8)$ & .18 \\
\hline ICU readmission & $16(4.0 \%)$ & $10(4.5 \%)$ & $3(2.4 \%)$ & $0(0 \%)$ & .58 \\
\hline Stage 2 or $3 \mathrm{AKI}^{*}$ & $14(3.5 \%)$ & $3(1.3 \%)$ & $5(4.0 \%)$ & $3(30.0 \%)$ & $<.001$ \\
\hline Dialysis & $7(1.8 \%)$ & $3(1.3 \%)$ & $0(0 \%)$ & $3(30.0 \%)$ & $<.001$ \\
\hline Death & $5(1.2 \%)$ & $1(0.4 \%)$ & $1(0.8 \%)$ & $1(10.0 \%)$ & .08 \\
\hline
\end{tabular}

Continuous variables are represented as median (25th-75th percentiles), and categorical variables as number (percent). $P$ values compare outcome distributions among patients grouped by [TIMP-2]·[IGFBP7] categories and represent Kruskal-Wallis test for continuous variables and chi-squared test for categorical variables. ICU, Intensive care unit; $L O S$, length of stay; $A K I$, acute kidney injury; $C B P$, cardiopulmonary bypass; $O P C A B$, off-pump coronary artery bypass. *Within 48 hours of surgery. 
TABLE E5. AUROC, sensitivity, specificity, PPV, and NPV of [TIMP-2] [IGFBP7] with corresponding 95\% confidence intervals at each timepoint for prediction of stage 2 or 3 AKI within 48 hours of surgery with 0.3 and 2.0 thresholds

\begin{tabular}{|c|c|c|c|c|c|c|c|c|c|}
\hline \multirow[b]{2}{*}{ Timepoint } & \multirow[b]{2}{*}{ AUROC } & \multicolumn{4}{|c|}{ Cutoff of 0.3 [TIMP2]·[IGFBP7] } & \multicolumn{4}{|c|}{ Cutoff of 2.0 [TIMP2]·[IGFBP7] } \\
\hline & & Sensitvity & Specificity & PPV & NPV & Sensitvity & Specificity & PPV & NPV \\
\hline Induction of anesthesia & $0.53(0.37-0.69)$ & $0.21(0.05-0.51)$ & $0.77(0.72-0.81)$ & $0.03(0.01-0.09)$ & $0.96(0.94-0.98)$ & $0.14(0.02-0.43)$ & $0.97(0.95-0.99)$ & $0.15(0.02-0.45)$ & $0.97(0.95-0.98)$ \\
\hline $\begin{array}{l}30 \text { min after start of } \mathrm{CPB} \\
\text { or OpCAB }\end{array}$ & $0.52(0.36-0.68)$ & $0.21(0.05-0.51)$ & $0.67(0.62-0.72)$ & $0.02(0.00-0.07)$ & $0.96(0.92-0.98)$ & $0.07(0.00-0.34)$ & $0.97(0.94-0.98)$ & $0.08(0.00-0.36)$ & $0.96(0.94-0.98)$ \\
\hline $\begin{array}{l}\text { Immediately after CPB } \\
\text { or OpCAB }\end{array}$ & $0.71(0.58-0.82)$ & $0.85(0.55-0.98)$ & $0.62(0.57-0.67)$ & $0.07(0.04-0.13)$ & $0.99(0.97-1.00)$ & $0.15(0.02-0.45)$ & $0.93(0.90-0.95)$ & $0.07(0.01-0.24)$ & $0.97(0.95-0.98)$ \\
\hline ICU admission & $0.68(0.54-0.81)$ & $0.31(0.09-0.61)$ & $0.78(0.74-0.82)$ & $0.05(0.01-0.11)$ & $0.97(0.94-0.99)$ & $0.08(0.00-0.36)$ & $0.97(0.95-0.98)$ & $0.08(0.00-0.36)$ & $0.97(0.95-0.98)$ \\
\hline $6 \mathrm{~h}$ after ICU admission & $0.78(0.58-0.93)$ & $0.73(0.39-0.94)$ & $0.64(0.58-0.69)$ & $0.06(0.03-0.11)$ & $0.99(0.96-1.00)$ & $0.27(0.06-0.61)$ & $0.98(0.96-0.99)$ & $0.30(0.07-0.65)$ & $0.98(0.96-0.99)$ \\
\hline Postoperative day 1 & $0.75(0.59-0.90)$ & $0.67(0.35-0.90)$ & $0.67(0.62-0.71)$ & $0.06(0.03-0.12)$ & $0.98(0.96-1.00)$ & $0.33(0.10-0.65)$ & $0.94(0.91-0.96)$ & $0.15(0.04-0.35)$ & $0.98(0.96-0.99)$ \\
\hline Postoperative day 2 & $0.65(0.48-0.81)$ & $0.46(0.19-0.75)$ & $0.70(0.65-0.75)$ & $0.06(0.02-0.12)$ & $0.97(0.94-0.99)$ & $0.23(0.05-0.54)$ & $0.97(0.95-0.99)$ & $0.23(0.05-0.54)$ & $0.97(0.95-0.99)$ \\
\hline Postoperative day 3 & $0.65(0.42-0.89)$ & $0.56(0.21-0.86)$ & $0.76(0.71-0.81)$ & $0.07(0.02-0.15)$ & $0.98(0.95-1.00)$ & $0.11(0.00-0.48)$ & $0.99(0.96-1.00)$ & $0.20(0.01-0.72)$ & $0.97(0.95-0.99)$ \\
\hline $\begin{array}{l}\text { Sum of post-CPB } \\
\text { OpCAB and } 6 \text { hours } \\
\text { after ICU admission }\end{array}$ & $0.81(0.74-0.90)$ & $0.93(0.66-1.00)$ & $0.56(0.51-0.61)$ & $0.07(0.04-0.12)$ & $1.00(0.97-1.00)$ & $0.21(0.05-0.51)$ & $0.95(0.92-0.97)$ & $0.13(0.03-0.34)$ & $0.97(0.95-0.99)$ \\
\hline $\begin{array}{l}\text { Product of post-CPB } \\
\text { OpCAB and } 6 \text { hours } \\
\text { after ICU admission }\end{array}$ & $0.81(0.71-0.89)$ & $0.86(0.57-0.98)$ & $0.65(0.60-0.70)$ & $0.08(0.04-0.14)$ & $0.99(0.97-1.00)$ & $0.21(0.05-0.51)$ & $0.98(0.96-0.99)$ & $0.25(0.05-0.57)$ & $0.97(0.95-0.99)$ \\
\hline $\begin{array}{l}\text { Maximum of post-CPB } \\
\text { OpCAB and } 6 \text { hours } \\
\text { after ICU admission }\end{array}$ & $0.82(0.73-0.90)$ & $1.00(0.77-1.00)$ & $0.44(0.39-0.49)$ & $0.06(0.03-0.10)$ & $1.00(0.98-1.00)$ & $0.29(0.08-0.58)$ & $0.92(0.88-0.94)$ & $0.11(0.03-0.26)$ & $0.97(0.95-0.99)$ \\
\hline Sum of all timepoints & $0.82(0.71-0.91)$ & $0.93(0.66-1.00)$ & $0.59(0.54-0.64)$ & $0.08(0.04-0.13)$ & $1.00(0.98-1.00)$ & $0.14(0.02-0.43)$ & $0.99(0.97-1.00)$ & $0.29(0.04-0.71)$ & $0.97(0.95-0.98)$ \\
\hline Maximum of all timepoints & $0.82(0.72-0.91)$ & $1.00(0.77-1.00)$ & $0.18(0.15-0.23)$ & $0.04(0.02-0.07)$ & $1.00(0.95-1.00)$ & $0.57(0.29-0.82)$ & $0.81(0.77-0.85)$ & $0.10(0.04-0.19)$ & $0.98(0.96-0.99)$ \\
\hline
\end{tabular}

AUROC, Area under the receiver operating characteristic curve; $C B P$, cardiopulmonary bypass; $O p C A B$, off-pump coronary artery bypass; $I C U$, Intensive care unit. 